\title{
Smart Contracts, Blockchain and Distributed Ledger Technology (DLT) in the Work of a Lawyer ${ }^{1}$
}

\author{
Agnieszka Kubiak-Cyrul, Dariusz Szostek
}

\section{Blockchain, DLT2 - a Foundation of LegalTech}

A number of tools used within LegalTech 2.0. and 3.0. apply blockchain and distributed ledger technologies ${ }^{3}$. This is not a new technology, the concept of distributed record keeping is over 50 years old (a memorandum no. RM-340-PR by Paul Baran ${ }^{4}$ from 1964). What is innovative, is its application in a law firm and its adaptation to the needs of lawyers. Blockchain has been around for a number of years (paper by a 'Satoshi Nakamoto ${ }^{5}$, from 2008) and has been identified by, among others, the European Union

1 The chapter was written thanks to financial support from the National Science Center, as part of project No. 2017/27 / B / HS5 / 01376.

2 A detailed description of the matter of blockchain and DLT exceeds the bounds of this monograph. The authors restrict themselves only to pointing out problems at the junction of LegalTech and blockchain technology. For more on the subject of blockchain: Szostek, (n 55); Marcelo Corrales, Mark Fenwick, Helena Haapio (eds), Legal Tech, Smart Contracts and Blockchain, (Springer 2019); Makoto Yano,Chris Dai, Kenichi Masuda, Yoshio Kishimoto, 'Creation of Blockchain and a New Ecosystem' in Makoto Yano, Chris Dai, Kenichi Masuda, Yoshio Kishimoto (eds) Blockchain and Crypto Currency, (Springer 2019); Georgios Dimitropoulos, 'The Law of Blockchain' (2020) 1117 Washington Law Review 11; European Parliamentary Research Service, 'Blockchain and the General Data Protection Regulation', PE 634.445 (2019) 4, <https://www.europarl.europa.eu/RegData/et udes/STUD/2019/634445/EPRS_STU (2019)634445_EN.pdf $>$ accessed 10 October 2020; Deborah Maxwell, Chris Speed, Larissa Pschetz, ,Story Blocks: Reimagining Narrative through the Blockchain.' (2017) 23 Convergence 79; Nicholas Roth, 'An Architectural Assessment of Bitcoin: Using the Systems Modeling Language' (2015) 44 Procedia Computer Science 527.

3 The European Union Blockchain Observatory \& Forum, EU Blockchain Ecosystem Developments, <https:/www.eublockchainforum.eu/sites/default/files/reports/EU\% 20Blockchain\%20Ecosystem\%20Report_final_0.pdf accessed 2 January 2021.

4 Paul Baran, 'On Distributed Communications: I. Introduction to Distributed Communications Networks` (1964) RAND Corporation <https://www.rand.org/ pubs/research_memoranda/RM3420 .html.> accessed 1 December 2020.

5 Satoshi Nakamoto, 'Bitcoin: A Peer-to-Peer Electronic Cash System ' 31 October 2008) $<$ https://nakamotoinstitute.org/bitcoin/> accessed 1 December 2020. The 
as a technology that is already affecting the way countries, institutions and societies function, and is expected to affect them even more significantly in the future. Both Paul Baran and Satoshi Nakamoto proposed their solutions having in mind the need to keep data safe and secure from any attack, be it physical or electronic.

The security component was also pointed out by Mariya Gabriel (Commissioner for Digital Economy and Society), who stated that "Europe must make more of technological innovation and Blockchain technology is an innovation that Europe cannot afford to miss. At the same time, it is clear that we need strong governance if we want to get the most out of distributed ledger technologies for the general interest, that means for our economy and for our society (...)Why are distributed ledger technologies relevant? The answer relates to a deeply human concept, trust. (...) Trusting the other side to honour their commitments, that is what gives them power and makes them useful. (...) In today's economy, however, there is less and less time to build trust in the way it happened in the past. (...) How can we achieve this? (...) Blockchain achieves this by removing the need to put trust into individual contractual partners. (...) But blockchain technology is not only useful in such familiar settings of individual transactions. There are other areas in which it can help us to establish system-wide trust. (...) However, Distributed Ledger Technologies are about much more than exchanging data in a safe manner. They allow us to rethink entirely existing business processes from scratch. (...)It is in this context that Blockchain and other DLT show their greatest potential: They can fuel new user-centric solutions that put individuals at the centre and give them control over their online identity, their data and their privacy. That is the promise. A technology to lift the decentralisation of the web and of the internet to a new level" ${ }^{6}$.

The law governs social relations. Legal engineering implements the law and codes, while trust is guaranteed by blockchain. It is for that reason the use of the latter within the framework of LegalTech is obvious, in many aspects. In the academic literature, authors distinguish three categories of blockchain ${ }^{7}$ : 1.0, 2.0, and 3.0. This classification was introduced having recognised the way in which blockchain is used. Blockchain 1.0,

real first name and surname of the author(s) of that work is not known, it was published under a pseudonym.

6 Speech by Commissioner for Digital Economy and Society Mariya Gabriel on blockchain applications, Brussels 3 April $2019<$ https://ec.europa.eu/commission/p resscorner/detail/en/SPEECH_19_1973> accessed 2 December 2020.

7 Melanie Swan, Blockchain - A Blueprint for a New Economy (O`Reilly 2015) $1 \mathrm{ff}$. 
or "the original blockchain" according to M. Swan, refers exclusively to S. Nakamoto's project and its use in cryptocurrencies. Blockchain 2.0 is used to transfer "value" other than currency. It covers the tokenisation of, inter alia, securities, as well as other assets - such as copyrighted works, real estate, etc. Smart contracts are also recognised in this group. For the purposes of this chapter, Blockchain 3.0 is most important. It includes the applications to the benefit of the judiciary, based on blockchain and using a decentralised IP cloud protection, as well as digital identity verification and authentication. In this way, services provided by central or local government are replaced in whole or in part. Blockchain 3.0 applications offer advantages in terms of scale, efficiency, organisation and coordination in the fields of science, genomics, health, academia and academic publishing, development, aid and culture, where people themselves - instead of the state or public authorities - mutually certify certain facts ${ }^{8}$. This also paves the way for interaction of humans and machines.

Blockchain technology is used at every stage of LegalTech, including both LegalTech 1.0 (eg. blockchain-based registries), LegalTech 2.0 (eg smart contracts, tokenisation of processes, crypto-assets) and finally LegalTech 3.0 (using AI in the judicial system of Estonia ${ }^{9}$ ).

\section{Influence of Blockchain on the New Paperless Approach. Datafication of the Law.}

Datafication, which means access to data instead of traditional formatted documents, is a major trend within the new paperless approach. It is also part of the development of LegalTech ${ }^{10}$, linked to the promotion of DLT, blockchain and smart contract in Europe. The essence of blockchain is the cryptographic protection of data saved in blocks. Cryptography, as a tool, makes that data immutable and by extension guarantees its veracity. Until now, the guarantors of the authenticity of data (or more broadly documents) have been individuals representing professions of public trust - such as a judge, notary, lawyer, solicitor. Where blockchain technology comes into play - such guarantors are cryptography and algorithms.

8 ibid 53-68.

$9<$ https://e-estonia.com/artificial-intelligence-as-the-new-reality-of-e-justice/> accessed 1 December 2020.

10 For more on the subject of datafication, see chapter on electronic communication in an organisation. 
There are various ways of securing blocks, and thus the security of stored data. The latter depends on the number of nodes and on the type of cryptography securing the nodes. Not all blockchains are deemed equal. Among the blockchains in operation, one can find those impossible to break today (in terms of their cryptographic protection) and those that do not offer such protection. As a result, the immutability of the data entered into a blockchain varies, which should be borne in mind by lawyers when analysing IT systems. Blockchain operates in distributed registers. What is important from a legal point of view, is that the data recorded on each node, regardless of the number of nodes, is the 'original' recorded data and can therefore be uploaded by a court or other authority from any such node. This is an active tool, in opposition to traditional documents entries occur in a constant manner and in real-time, sometimes even a few hundred thousand entries during a single day.

At the present time, there is no uniform European regulation regarding the relationship between an entry in a blockchain and the legal presumption of the veracity of a fact recorded in a block. Some countries have introduced such regulations. Some of them have done it in a general way, such as Singapore ${ }^{11}$, while others have decided on specific provisions for certain categories of entries, such as those related to cryptocurrencies ${ }^{12}$ or securities. This situation is expected to change in the near future, as work is underway on EU regulations that would link blockchain entry to legal presumptions. Efforts to link entity identification, as well as the Internet of Things (IoT), to the use of attributes entered in blockchain are well advanced. The announced developments are aimed at promoting blockchain and making it more attractive as a tool, including within LegalTech. Blockchain is a tool that displaces public trust entities, but also a tool that supports such entities.

\section{Using Blockchain in LegalTech}

In the 21st century, blockchain is becoming a technological, automated but also democratised tool which is analogous to traditional public trust

11 Evidence Act (Chapter 97) Relevancy of Facts <https://sso.agc.gov.sg/Act/EA1893> accessed 25 October 2020.

12 Act No. XXXI of $2018<$ https://mdia.gov.mt/wp-content/uploads/2018/10/MDIA.p df $>$ accessed 2 December 2020. 
institutions. It does not replace them or their functions, but achieves similar goals, either on its own or by complementing existing institutions.

The speed of data generation, its complexity, datafication and the high frequency of transactions make it impossible to maintain the current classical way of data authentication. Moreover, for many types of data it is unworkable (eg IoT data). For this reason, the use of blockchain in LegalTech is becoming increasingly accepted and, in time, will become common practice. Certain trends are evident for blockchain:

1) with regard to legal presumptions:

a) as a modern database (without links to legal presumptions),

b) as a database which link blockchain entry to legal presumptions,

2) with regard to self-reliance:
a) functioning as support for a human, with entries made in a tradi- tional manner by a specific person(s),
b) functioning in a fully automated manner, for instance through a smart contract, automatic storing of data from IoT etc.,
c) hybrid, after acceptance by an authorised person or an authorised institution, an automated entry,

3) with regard to manner of use:
a) as a component of other, more complicated LegalTech solutions (eg smart contract, durable medium),
b) solely as a database,

4) with regard to the entity using it:
a) public blockchain,
b) private blockchain,
c) government,
d) corporate,
e) business-oriented, etc.,

5) with regard to its territorial reach:
a) local,
b) state-wide,
c) cross-border,
d) aterritorial, where it is impossible (even indirectly) to establish a link with a given territory (eg Bitcoin).

The advantages of using blockchain include the elimination or reduction of the role of traditional intermediaries, the ability to obtain data attestation online without physical contact, unlike in case of traditional public trust institutions, and the auditability of blockchain, which guarantees its transparency and accountability. The application of blockchain in LegalTech is very diverse and subject to rapid development. For instance, 
blockchain is used in InsureTech ${ }^{13}$ - insurance (eg through smart contract, but also data analysis from IoT). It is also used in the energy sector, both in the scope of renewable energy projects, its redistribution, in smart energy meters, and in client databases. Smart contracts and crypto-currencies are based on blockchain, yet it is found also in traditional banking, settlement, and in creation of electronic money. Blockchain is used to certify documents, data, and entries (or rather, to guarantee their veracity, without the need of additional certification), in traditional logistics, and in humanitarian aid. It is used in craftworking, dematerialisation of securities, and for trade in such securities. The same may be said for attestation of copyright, patents, and for certification of origin for goods (EUiPO Blockathon). The same can be said of the legislative process monitoring, identity registers, electronic voting, general meetings of company members, managing company affairs solely in blockchain, and permanent data storage. It is further used as a register (for instance, as a company register or a land register), as a tool supporting notaries, the courts and public administration, and in the scope of taxes, control thereof, immutability of transactions, and in many other projects, including those at the intersection of the world of humans and that of machines.

Only for the purposes of providing examples and inspiration, certain models of using LegalTech based on blockchain are presented below. Among them, one of the boldest examples that modify prior legal concepts is found in the formation of the Blockchain-Based Limited Liability Companies (BBLLC) which operate only in a virtual manner and in a network, based on DLT and blockchain, with no physical company seat. A BBLLC is regulated by the act no. 205 relating to blockchain business development (Vermont, US). Such a company operates solely through algorithmic protocols defining, among other things, consensus rules, while the corporate resolutions passed by the company operate through smart contracts. An entry in blockchain is linked to a legal presumption. A BBLLC company is a conventional company carrying out business activities, what is new is the way it is organised and managed (based on LegalTech) ${ }^{14}$.

Another example is found in one of the biggest global blockchain projects ${ }^{15}$, implemented by Maersk and other carriers (eg Hapag-Lloyd and ONE - respectively - fifth and sixth shipping companies in the world by

13 Pierpalo Marano, Dariusz Szostek, Smart Contract and Insurance (Palgrawe McMillan 2021).

14 See Dariusz Szostek, Blockchain and the Law (1 ed., Nomos 2019) $136 \mathrm{ff}$.

15 TradeLens Blockchain. 
size), within the framework of which there are thousands of entries being made daily ${ }^{16}$, with said entries following from smart contract and operations on data. This includes transfer of ownership, the entry of goods into a given legal area, customs, etc. Interesting examples of regulation, and examples of blockchain-based LegalTech solutions, have emerged in the US. A blockchain entry meeting the written form requirement of the document has been proposed (an Act no. HB 1944, Arizona). In California, the entry of data from vital records has been linked with a presumption of veracity, without the need for physical certification (Senate bill no. SB-373 of 2019) ${ }^{17}$. Traditionally, law requires certified copies of birth, death, and marriage records be printed on chemically sensitized security paper with specified features, including, among others, watermarks, fluorescent fibers, and intaglio print. New law from 1.1.2022 would authorize a county to issue certified copies of marriage records by means of blockchain technology and would exempt those records from the required physical properties and features described above.

A bill no. SB-1 84 by the State of Colorado ${ }^{18}$ vests a duty in the Colorado Water Institute at the Colorado State University to study potential applications of blockchain technology for managing a database of water rights, to facilitate the establishment or operation of water markets or water banks, and for any other useful purpose in the administration of the institute's powers and duties, and to report the results to the general assembly of that State. In the State of Connecticut, under bill no. HB $5417^{19}$ there are acts taken in order to use blockchain to manage voter registration, mainly to prevent dual registration, while under bill ${ }^{20}$ no. HB 6062 blockchain is used for online voting. In the State of Illinois, there are statutes being introduced on using blockchain in transactions, procedures, and in public registers ${ }^{21}$, while in Kansas this applies to regulations on company registers that use blockchain. There was a statute passed in the State of

16 At the time of writing this chapter there were over 15 million documents entered $<$ https://www.tradelens.com/platform> accessed 8 December 2020.

$17<$ http://leginfo.legislature.ca.gov/faces/billNavClient.xhtml?bill_id=201920200SB3 73> accessed 7 December 2020.

$18<$ http://leg.colorado.gov/sites/default/files/documents/2019A/bills/2019a_184_01.p df $>$ accessed 6 December 2020.

$19<$ https://www.cga.ct.gov/2019/FC/pdf/2019HB-05417-R000081-FC.PDF > accessed 7 December 2020.

$20<$ https://www.cga.ct.gov/2019/TOB/h/pdf/2019HB-06062-R00-HB.PDF > accessed 7 December 2020.

21 <http://kslegislature.org/li/b2019_20/measures/documents/hb2039_enrolled.pdf accessed 7 December 2020. 
New York that relates to agreements and electronic signatures entered into blockchain, and to smart contracts ${ }^{22}$. A similar occurrence came to be in North Dakota ${ }^{23}$.

In Europe, central banks and regulatory bodies (as well as the European Central Bank) are deliberating the use of Euro in digital form, based on blockchain. This follows inter alia from the growing number of projects on digital currencies in Asia (People's Bank of China vigorously develops Central Bank Digital Currencies) ${ }^{24}$. The so-called 'stabilcoins' emerge electronic currencies fixed to state currencies by way of a "currency peg" 25 . Many states either implement blockchain in registers (eg Estonia, Georgia) or prepare such implementations. Blockchain is seriously considered for use in electronic identification ${ }^{26}$, including in eIDAS Regulation-related services ${ }^{27}$, and identification of persons, entities, attributes or IoT equipment. Professional legal associations are reaching for that technology eg notaries ${ }^{28}$, and other lawyers as well, inter alia in the scope of tokenisation of processes. The time of blockchain is upon us.

4.Smart contract - a LegalTech tool in pure form

One of the most advanced LegalTech tools available nowadays, and one that is gaining in popularity, is the smart contract. Based on private law, it combines legal engineering and algorithmic codes, translates natural language into codes, and may contain tokens. It is based on DLT and blockchain technology, and, as a consequence, in most cases ensures a high level of cybersecurity and AI can be used as an oracle. It is not a document in the traditional sense, but rather is based on dataisation ${ }^{29}$. The $\mathrm{EU}^{30}$ is

$22<$ https://nyassembly.gov/leg/?bn=A01683\&term=2019> accessed 8 December 2020.

23 <https://www.legis.nd.gov/assembly/66-2019/documents/19-0127-06000.pdf $>$ accessed 8 December 2020.

$24<$ https://www.eublockchainforum.eu/sites/default/files/reports/1st $\% 20$ EUBOF\%2 0Trend\%20Report_December\%202020.pdf s accessed 8 December 2020.

25 <https://tlaib.house.gov/sites/tlaib.house.gov/files/STABLE_Act_One_Pager.pdf $>$ accessed 7 December 2020.

$26<$ https://www.bmwi.de/Redaktion/DE/Publikationen/Digitale-Welt/blockchain-st rategie.pdf?_blob $=$ publicationFile $\& v=8>$ accessed 6 December $2020 ;<$ https://co nsensys. net/blockchain-use-cases/digital-identity/> accessed 6 December 2020.

$27<$ https://ec.europa.eu/futurium/en/system/files/ged/eidas_supported_ssi_may_201 9_0.pdf $>$ accessed 8 December 2020.

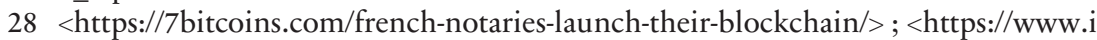
tone.lu/actualites/luxembourg-notary-blockchain-kickoff-first-europe $>$ accessed 7 December 2020.

29 See Malta.

30 See (indirectly related to the smart contract and directly to tokens): Proposal for a Regulation of the European Parliament and of the Council on Markets 
increasingly taking into account smart contracts in new legislation. This trend will continue to develop, and the use of smart contracts will become standard practice, and in the case of, for example, crypto assets ${ }^{31}$, it has already become the standard.

At the present time, a smart contract is classified as a LegalTech 2.0 tool. The development of AI and the increasingly bolder combination of the smart contract "oracle" with AI will result in the former being reclassified as LegalTech 3.0. ${ }^{32}$ The LegalTech 2.0 and 3.0 criteria concern the autonomy of decision-making. LegalTech 2.0 smart contracts follow pre-programmed sequences. At the present time, the vast majority of smart contracts fall within this group. On the other hand, the feasibility of a smart contract under LegalTech 3.0 depends on the decisions made by the algorithm after an independent analysis of the facts (at the moment we are at the stage of pilot schemes and small projects).

\section{Definition of a smart contract}

Both legal treatises on new technologies and EU documents include many publications, studies and monographs devoted to the theme of smart contracts, its principles of operation, definitions, aspects of its functioning, and related legal problems. However, these need not be repeated ${ }^{33}$ in this publication. This is because from the perspective of this monograph, we intend to focus on its application in LegalTech as a lawyer's working tool.

in Crypto-assets, and amending Directive (EU) 2019/1937, COM/2020/593 final $<$ https://eur-lex.europa.eu/legal-content/EN/TXT/?uri= CELEX:52020PC0593> accessed 21 January 2021.

31 <https://www.tradelens.com> accessed 21 January 2021.

32 See also Markus Hartung, Micha-Manuel Bues, Gernot Halbleib, Legal Tech. Die Digitalisierung des Rechtsmarkts (C. H. Beck 2018) 6.

33 See latest publications: Daniel Hellwig, Goran Karlic, Arnd Huchzermeier, Build Your Own Blockchain (C. H. Beck 2020) 74 ff; Maria Grazia Vigliotti, Haydn Jones, The Executive Guide to Blockchian (Palgrave Macmillan 2020) 133; Eranga Bandara, Wee Keong Ng, Nalin Ranasinghe, Kasun De Zoysa, 'Aplos: Smart contract Made Smart' in Zibin Zheng, Hong-Ning Da, Mingdong Tang, Xiangping Chen (eds), Blockchain and Trustworthy System (Springer 2020) 431; Robert Wilkens, Richard Falk, Smart Contracts, Grundlagen, Anwedungsfelder und rechtliche Aspekte (Springer 2019) 3 ff; Riccardo de Caria, 'Definitions of Smart Contracts: Between Law and Code' in Larry A. DiMatteo, Michel Cannarsa, and Cristina Poncibò (eds) The Cambridge Handbook of Smart Contracts, Blockchain Technology and Digital Platforms (Cambridge University Press 2019) 19 ff. 
The essence of a smart contract, as described by $R$. Wilkens and $R$. Falk $^{34}$, consists simply in a set of algorithmic codes in a properly prepared computer program, entered and based on data in a blockchain operating on the "if-then" logic. Activating a smart contract constitutes an automatic execution of a predefined legal (eg making a transfer), procedural (eg entry in the register) or purely factual (eg sharing digital content) act, in connection with the occurrence of a predefined event, both events that are factual in form and events bearing the characteristics of a legal transaction. In information terms, a smart contract is an algorithmic code capable of achieving the correct execution of the terms of a contract ${ }^{35}$.. One example of a simple system that we have been familiar with for years, is the simple vending machine. Today's smart contracts in LegalTech 2.0 or 3.0 form are much more complicated and complex. It should be pointed out at the outset that the smart contract, despite its name, is not always a contract in a legal sense. Not only that, but depending on the discipline, it also is understood differently by lawyers, computer scientists and economists.

At the present time, different countries have adopted different approaches to smart contract legislation, ranging from a complete absence of any reference to such contracts (where its operation is based on the principle of freedom of contract) to the implementation of statues containing descriptive definitions ${ }^{36}$ (eg of tokens, platforms, etc.) or legal definitions ${ }^{37}$.

The Maltese definition ${ }^{38}$ adopted by the Malta Digital Innovation Authority Act $^{39}$ to explain the essence of a smart contract, deserves special attention. A Smart contract is defined here as an algorithm that automatically executes at least part of a contract. The contract itself can be concluded in its entirety in electronic form (we cannot determine by its form

34 Robert Wilkens, Richard Falk, Smart Contracts, Grundlagen, Anwedungsfelder und rechtliche Aspekte (Springer 2019) 4.

35 Merit Kõlvart, Margus Poola, Addi Rull, 'Smart Contracts' in Tanel Kerikmäe, Addi Rull (eds) The Future of Law and eTechnologies (Springer 2016) $134 \mathrm{ff}$.

36 Singapore - Electronic Transactions Act $<$ https://sso.agc.gov.sg/Act/ETA2010\#P1I $>$ accessed 27 January 2021.

37 See Arizona, Belarus, Malta.

38 Art. 2, para. 2: "A smart contract: means a form of innovative technology arrangement consisting of: (a) a computer protocol; and, or (b) an agreement concluded wholly or partly in an electronic form, which is automatable and enforceable by execution of computer code, although some parts may require human input and control and which may be also enforceable by ordinary legal methods or by a mixture of both.".

39 See $<$ https://parlament.mt/media/95199/act-xxxi-malta-digital-innovation-authorit y-act.pdf $>$ accessed 27 January 2021. 
whether it is to be concluded on the platform or via e-mail, or entered in a blockchain, etc.) or in traditional form (eg on paper) fully or partly (eg as a framework agreement). It can refer to named, unnamed, and mixed contracts.

In civil law terms, a smart contract is not always a contract. Its performance should take place automatically thanks the occurrence of predefined facts, while both activating contract performance or execution may require human action (eg by human activation of the algorithm). Contract enforcement may be fully automated, but traditional enforcement must also be acceptable. A contract may operate under one jurisdiction, but very often it operates simultaneously in many. A smart contract agreement may also be governed by various applicable laws (in the absence of a choice of law in the contract, its search is based on classic conflict of laws rules). It can operate as a single-step (performance of a single act), multi-step agreement (the performance of one act triggers another), or, finally, in continuous formats (through continuous interactions and entries in the blockchain). Evidence of the performance of a smart contract is registered in the blockchain, which requires lawyers to acquire new skills in the scope of gathering evidence. For this reason, increasingly legislation is being introduced on an ever more frequent basis aimed at binding an entry to a blockchain with a legal presumption ${ }^{40}$.

\section{Examples of the application of the smart contract in LegalTech}

In the past, smart contracts were associated almost exclusively with transactions involving bitcoin or other cryptocurrencies. The technology has long since gone beyond this limited scope and is being applied in innovative ways in many sectors of the economy. The number of transactions made daily on the basis of smart contracts in a DLT (distributed ledger technology) environment is growing rapidly. According to data gathered by Dune Analytics, approximately 670,000 smart contracts are executed every month in the Etherneum blockchain alone ${ }^{41}$. Although not all smart contracts involving the implementation of legal actions, the above data point to the popularity of this tool and the versatility of its application.

40 See the chapter: Blockchain and DLT the Work of a Lawyer.

41 Joshua Mapperson, Ethereum Smart Contracts up $75 \%$ to Almost 2M in March $<$ https://cointelegraph.com/news/ethereum-smart-contracts-up-75-to-almost-2m-in -march $>$ accessed 27 January 2021. 
Initially, most investments in solutions based on distributed ledger technology and smart contracts were carried out in the banking sector. Currently, such investments can be observed in most sectors of the economy.

Recently, Forbes published a list of the 50 largest entities that use blockchain technology and smart contracts in their operations ${ }^{42}$. They included the following giants: A.P. Moller-Maersk Denmark (logistics, maritime container shipping - blockchain: TradeLens, Hyperledger Fabric, IBM Blockchain), Ant Group China (an entity connected with the holding Alibaba Group, blockchain: AntChain, Hyperledger Fabric, Quorum), BHP Australia (mining industry, blockchain: MineHub, Hyperledger Fabric), Boeing USA aviation transport, blockchain: Go Direct, Hyperledger Fabric), Carrefour France (supermarket chain, blockchain: IBM Blockchain, Hyperledger Fabric), Credit Suisse Switzerland (financial services, blockchain: Enterprise Ethereum, Paxos Settlement Service), Daimler Germany (automotive industry, blockchain: Hyperledger Indy, Hyperledger Fabric, Corda, Ocean Protocol, Ethereum, MoveX), Equinor Norway (fuel and energy industry, blockchain: Data Gumbo, Vakt), Novartis Switzerland (pharmaceutical industry, blockchain: Ethereum, Sovrin, Hyperledger Fabric, Corda, DAML, Quorum), Walmart USA (supermarket chain, blockchain: Hyperledger Fabric), Visa USA (payment services, blockchain: Bitcoin, Ethereum), Samsung Group South Korea (electronics industry, blockchain: Nexledger $)^{43}$ etc.

Smart contracts have been used in the insurance services sector for several years now. ${ }^{44}$. In 2018, a consortium comprising EY, Guardtime, Møller-Maersk and Microsoft developed and launched the Insurwave platform. It uses blockchain and smart contracts to automate insurance contracts in maritime transport. This platform collects data on a vessel and its cargo from various sources in real time. The occurrence of events specified in the smart contract, information on which is provided via the Oracle function, triggers, eg the payment of compensation, without the need to

42 Michael del Castillo, Blockchain 50 2021, <https:/www.forbes.com/sites/michae ldelcastillo/2021/02/02/ blockchain-50/?sh=207076dc231c > accessed 27 January 2021.

43 Michael del Castillo, Forbes Blockchain 50 Of 2021: Cashing In On Bitcoin Mania $<$ https://www.forbes.com/sites/michaeldelcastillo/2021/02/02/forbes-blockchain -50-corporate-america-cashes-in-on-bitcoin-mania/?sh=1bc729216e01>accessed 27 January 2021.

44 OECD, Technology and innovation in the insurance sector (2017) <https://www.oecd. org/pensions/Technology-and-innovation-in-the-insurance-sector.pdf $>$ accessed 27 January 2021; Marano, Noussia (n 13). 
prepare any additional documentation. This technology also works well in parametric insurance.

One example of such insurance was Fizzy, a flight delay test insurance scheme marketed by the AXA group ${ }^{45}$. The insurance contract specifies a predetermined amount that will be paid after meeting the condition indicated. The payment obligation is expressed in machine language in the smart contract, which is stored in the Etherneum blockchain. As a result, its activation may result in the automatic payment of compensation without the need to complete any formalities and go through the claim settlement process, if the smart contract algorithm was thus constructed. The construction of such a smart contract features Oracle functions enabling the user to obtain information on the actual times and dates of aircraft take-offs and landings.

Based on the same principle, smart contracts can also be developed for insurance contracts concluded in the event of drought, hurricane, floods, heavy rain, etc. The selected policy conditions (eg price, planned departure time, amount of compensation) will be saved in the form of a smart contract in the blockchain. Changing the terms of such an agreement is not possible once the smart contract has been introduced into the blockchain. The decision-making regarding the payment of compensation has been fully automated and based on transparent rules, which eliminates the risk of potential disputes between the insurer and clients. The dissemination of blockchain technology in the insurance sector may serve as a foundation for specialized insurance products that provide protection against various types of risk, based on external data provided by reliable entities.

Another sector in which blockchain and smart contract technology is rapidly gaining a foothold is energy, in particular the pro-consumer electricity market. ${ }^{46}$. Blockchain is used to build order and contract management systems. It is also useful platform for developing tools for direct sales of

45 See <https://www.axa.com/en/magazine/axa-goes-blockchain-with-fizzy $>$ accessed 27 January 2021. The insurance was available to customers during the period from 9.2017 to 11.2019 .

46 Joseph Lee, Vere Marie Khan, 'Blockchain and Smart Contract for Peer-to-Peer Energy Trading Platform: Legal Obstacles and Regulatory Solutions‘ (2020) 19 UIC REV. INTELL. PROP. L. $285 \mathrm{ff}$; Qiang Wang, Rongrong Li, Lina Zhan, 'Blockchain technology in the energy sector: From basic research to real world applications' (2021) 39 Computer Science Review; Merlinda Andoni, Valentin Robu, David Flynn, Simone Abram, Dale Geach, David Jenkins, Peter McCallum, Andrew Peacock, 'Blockchain technology in the energy sector: A systematic review of challenges and opportunities' (2019) 100 Renewable and Sustainable Energy Reviews. 
energy in a peer-to-peer network as well as for improving and developing electric car charging stations. The most advanced activities using blockchain and smart contract technologies are undertaken by the German energy network operator E.ON and the Italian company Enel. In 2017, they introduced blockchain transactions that do not require the participation of intermediaries and are performed in real time, which significantly reduces distribution costs for the end customer. The next step is "energy tokenization". This requires the conversion of energy into contractual units, i.e., tokens, which can then be sold to recipients via smart contracts based on the same principles governing the operation of prepaid cards. The launch of Enerchain ${ }^{47}$ in 2019 may accelerate the development of new forms of distribution for energy products. This is a trading platform for 44 energy companies based on blockchain technology, which enables the user to trade in various energy and gas products.

Blockchain is also used to create modern systems for registering property titles and real estate transactions. One example of an advanced platform based on blockchain technology and smart contracts is a real estate registry created for Georgia. It was prepared by Bitfury Group in collaboration with the Georgian National Agency of Public Registry (NAPR) ${ }^{48}$. The system provides a new and secure way of registering real estate that at the same time gives owners greater control over their property. Property ownership records are stored in the Exonum blockchain and are additionally secured in the bitcoin blockchain. The legal title to a property is documented by digital certificates supported by cryptographic evidence (a hash). This is a fully decentralized, secure digital system that is more efficient than its traditional counterpart and is corruption proof, thereby ensuring greater levels of trust among citizens. In the event of the sale or transfer of property ownership, the system saves new owners time and costs during the registration of such actions. In addition, it provides a transparent history of transactions and any changes in information regarding a given property. All blockchain processes can easily be audited both in real-time and retrospectively, which is important from the perspective of real estate registers. Work on planned real estate registers using blockchain and smart

47 See <https://enerchain.ponton.de/index.php/37-enerchain10live > accessed 27 January 2021.

48 Nino Lazuashvili, Alex Norta, Dirk Draheim, 'Integration of Blockchain Technology into a Land Registration System for Immutable Traceability: A Casestudy of Georgia' in Claudio Di Ciccio and others (eds) Business Process Management: Blockchain and Central and Eastern Europe Forum (Springer 2019) $72 \mathrm{ff.}$ 
contract technologies is also at an advanced stage in a number of other countries, such as Sweden ${ }^{49}$, Great Britain ${ }^{50}$ and India ${ }^{51}$.

Very promising innovations based on blockchain and smart contract solutions have been introduced in the area of copyright management, in particular in the form of systems for distributing fees paid to authors for the commercial use of their works. Blockchain-based platforms are beginning to emerge that use smart contracts to provide users with digitized music, such as UJO Music ${ }^{52}$. A pioneer in this regard was the British artist Imogen Heap, whose work Tiny Human was first made available to recipients via a smart contract. When the user pays a fee in cryptocurrency or in a digital currency for access to a work, the smart contract automatically pays the sum due to each entitled artist according to an earlier concluded contract included in the distribution algorithm. This is done immediately after the work is shared and without the need for intermediaries. The use of blockchain and smart contracts in this regard naturally requires determining who is entitled to receive royalties. This technology also enables the efficient transfer of fees to copyright collectives. For this reason, in 2017 Spotify, the Swedish global streaming service offering access to music, acquired the start-up Mediachain Lab, which develops blockchain-based projects ${ }^{53}$. It will be used to create a database of artists and their works in combination with license agreements, which will make it possible both to automate the distribution of works to users as well as

49 For more on this topic: "The Land Registry in the blockchain - testbed. A development project with Lantmäteriet, Landshypotek Bank, SBAB, Telia company, ChromaWay and Kairos Future" <https://chromaway.com/papers/Blockchain_La ndregistry_Report_2017.pdf $>$ accessed 27 January 2021; Shefali Anand, A pioneer in real estate blockchain emerges in Europe, <https://www.wsj.com/articles/a-pione er-in-real-estate-blockchain-emerges-in-europe-1520337601> accessed 27 January 2021; Molly Jane Zuckerman, Swedish government land registry soon to conduct first blockchain property transaction <https://cointelegraph.com/news/swedish-governm ent-land-registry-soon-to-conduct-first-blockchain-property-transaction $>$ accessed 27 January 2021.

50 See HM Land Registry to explore the benefits of blockchain <https://www.gov.uk/gove rnment/news/hm-land-registry-to-explore-the-benefits-of-blockchain> accessed 27 January 2021.

51 Vinay Thakur, M.N. Doja, Yogesh K. Dwivedi, Tanvir Ahmad, Ganesh Khadanga, 'Land records on Blockchain for implementation of Land Titling in India' (2020) 52 International Journal of Information Management.

52 See $<$ http://ujomusic.com/> accessed 27 January 2021.

53 Hugh McIntyre, 'Spotify Has Acquired Blockchain Startup Mediachain' <https:// www.forbes.com/sites/hughmcintyre/2017/04/27/spotify-has-acquired-blockchain -startup-mediachain/?sh=6c9ffaf369ee $>$ accessed 27 January 2021. 
make payments to entitled authors. The core element in this solution is a properly prepared smart contract, one that correctly executes the terms of contracts concluded between artists, entities providing streaming services, and consumers. It is not only commercial entities that nowadays see the benefits of blockchain and smart contracts. In 2020 the World Intellectual Property Organization (WIPO) began developing a system of intellectual property rights registration based on this technology ${ }^{54}$.

The above examples do not give a full picture of the practical applications of blockchain and smart contract technologies. These solutions have enormous potential and are undergoing rapid development. The smart contract should eventually be as ubiquitous in our daily lives as the Internet, Word, e-mails, ZOOM, electronic payments, Facebook etc. Its growing importance should be accompanied by greater awareness of the principles governing the operation of this technology as well as, and even more importantly, its limitations. In particular, it requires lawyers whose clients have the right to expect professional and competent support in matters relating to blockchain and smart contracts. The basic problems concerning the use of smart contracts in contract performance will be presented below.

\section{Legal problems connected with the use of smart contracts in LegalTech}

The life cycle of smart contracts can be broken down into several phases. From a lawyer's perspective, the most important stage in this cycle is the actual creation of the contract. The interested entity (or entities) formulate the content of the draft agreement, specifying in particular the rights and obligations of the parties. Usually, not all elements of the contract can be automated. It is therefore necessary to specify which parts should be written in the form of a smart contract. Next, coding specialists must create a smart contract algorithm, that is, convert an agreement written in natural language into machine language. The programming languages most widely used for this purpose are Solidity, Go, Kotlin and Java. Databases already exist that contain ready-made code snippets in open source access, which coders use in the same way as lawyers use standard contractual clauses.

54 WIPO Standards Launches Webinar Series with Blockchain for IP $<$ https://www. wipo.int/standards/en/news/ 2020/news_0001.html> accessed 27 January 2021. 
The programming language requires the content of the smart contract to be formulated in an unambiguous way, dispelling any doubts as to the expected result. However, programmers should take care to ensure that the intentions of the parties regarding the contract are executed partially or fully on the basis of the smart contract. This is not an easy task as they lack adequate legal knowledge. As a consequence, in the case of complex legal relationships, there is a concern that the technical limitations of the programming language and the lack of appropriate expertise on the part of the code's creator will result in the non-performance or improper performance of the contract. For this reason, close cooperation between programmers and lawyers is very important at this stage. The success of this collaboration depends on achieving mutual understanding between both sides.

Translating the meaning of certain concepts from legal language into machine language is very difficult in practice, because lawyers and programmers use their languages for very specific (different) purposes. Contracts often contain abstract, ambiguous concepts (eg, responsibility, good faith, due diligence, forthwith), which allow a certain flexibility in the contractual relationship. However, creating a computer program requires precise, clear and unambiguous instructions for the computer. This means that not all contractual terms can be represented in machine language. The literature emphasizes the need to distinguish between different types of clauses in contracts. Not all clauses are equally susceptible to automation or their automation is not always desirable when the interests of the parties are taken into account.

A binary code is compiled on the basis of this version of the smart contract. Special software (a compiler) is used for this purpose. it transcribes the notation used in the language, eg Solidity, into machine instructions expressed in bytecode. This is another way of transforming the parties' intentions expressed at the time of the contract's conclusion. If this software contains bugs or was poorly designed, it may result in significant discrepancies between what the parties intended to achieve and what will be implemented after the smart contract is executed. The designed algorithm should then pass through the implementation and validation phases. In particular, the smart contract should be carefully checked to ensure it does not contain any potential errors or gaps. Unfortunately, this stage requires specialist knowledge, which means that it is not always properly executed. Repeated tests should be performed in an isolated environment, because a smart contract has real consequences that cannot be undone once the blockchain is running. Once the results are correct, the smart contract enters the implementation phase. However, even when appropriate tests 
have been carried out, there is no guarantee that the smart contract will not contain errors or gaps that, when introduced into the chain, will have negative results.

The new transaction is transferred to the network together with the proposed fee expressed in GAS units and the indicated currency portfolio from which the fee is to be collected ${ }^{55}$. As a consequence, a certain degree of unpredictability should be expected regarding the commencement date of a smart contract, and thus the performance of the contract itself. Insufficient GAS will result in the transaction being rejected. If the amount of GAS was adequate, the transaction after verification must be packed into a block by miners, and then a new block must be added to the blockchain. This process is beyond the control of the parties to the smart contract. The time required to complete the tasks written in the algorithm is also difficult to predict. Smart contract execution usually entails making changes to the blockchain (eg transfers of cryptocurrencies or digital currencies between the addresses indicated in the smart contract). They are saved and distributed to all nodes in the chain.

The above stage concludes by placing the smart contract on the Etherneum blockchain and assigning it an individual address. From this moment, the smart contract can no longer be modified and is available to all blockchain users. Accessing this address enables the user to visualize certain data, such as the balance and the application binary interface (ABI). Each smart contract is identified by its software code associated with a specific block address, eg 0xbF35fAA9C265bAf50C9CFF8c389C363B05753275. It also has its own name, eg crowdsale, token, or mytoken. However, these names are repeated very often and do not have the power to individualize a given smart contract.

At the smart contract execution stage, problems may arise with the credibility and reliability of the source providing the information required to activate the action stored in the algorithm. This is the case only with

55 In the case of the Ethereum platform, consensus is achieved through the PoW algorithm. The Ether (ETH) cryptocurrency is used to reward miners that approve a transaction. To ensure the independence of the variable value of this cryptocurrency, the GAS unit is used in internal settlements, in which the price for transaction verification is determined. The transaction cost is determined as the product of the maximum amount of GAS units needed to generate the block and the GAS price specified in ETH. A party that wants to run a smart contract declares the payment of a certain amount of GAS in return for confirmation of the transaction (the greater the amount of GAS, the greater the motivation for miners to act). For more on this topic $<$ https://ethereum.stackexchange.com/questions/27452/how-to -estimate-gas-cost $>$ accessed 27 January 2021. 
those smart contracts that have been programmed in a way that allows them to obtain data from outside the blockchain. The function that developers use to achieve this is called an "oracle". In simple terms, an oracle is a system that provides a smart contract with information from the outside world (eg regarding the temperature, wind strength, share prices, match results, plane landing times, courier deliveries, etc.) In a format which can be processed in a blockchain environment. The use of the oracle function requires making a payment to GAS each time. As a result, insufficient amounts of GAS in the indicated portfolio will prevent the acquisition of external data and the implementation of the smart contract. If a smart contract with an oracle function supports the execution of the contract, the parties should at the negotiation stage determine what or who will be a reliable source of the data on which the algorithm will depend. The credibility of this data is not subject to any formal or material verification by network participants. In addition, even if the selected data source is reliable, it may be the case that the external data received by that source was incorrect. Aware of the above consequences, the parties to a smart contract should thus agree on a reliable source of information in their case. This factor is the root of numerous technical and legal problems.

The above brief presentation of the principles governing the operation of a smart contract in a blockchain highlights the key role that technical aspects of this tool play when it is used to perform contractual obligations. By being aware of the limitations of this tool lawyers will be able to ensure that their clients avoid significant problems when acting on the basis of blockchain technology.

\section{Summary: Should lawyers be smart?}

A smart contract is written in a machine language, which most lawyers regard as a foreign language. Given this fact, how can such lawyers be sufficiently qualified to advise a client on a smart contract if they do not understand it themselves? There are only three options for solving this problem. First, lawyers must work closely with developers on such matters. However, we should be aware of the fact that while an IT specialist will explain what is written in the algorithm, a lawyer will have to imagine the legal consequences of running this algorithm in the blockchain. The second solution assumes that a lawyer will learn the rules of coding to a sufficient standard to be able to understand the content of the smart contract. Over time, further modifications in machine languages should make them much easier to understand. This was the case with operating 
systems whose interfaces have become increasingly user-friendly. Finally, the third assumption is that in the future, artificial intelligence will replace lawyers in analysing the functioning of smart contracts. However, this development remains in the distance future. Meanwhile, we should expect to see the emergence of new third party liability insurance products in conjunction with legal services for entities operating on the basis of blockchain and smart contract technologies.

In the future, blockchains will become part of the legal services industry. If this does not happen through the initiative of lawyers themselves, it will result from the pressure exerted by their clients. On the one hand, major business entities, i.e., the biggest clients of law firms, are already carving out new areas of activity based on blockchain and smart contracts or are seeking development opportunities connected with these technologies. They will expect legal support in these areas. It would seem that only lawyers who make an effort to learn about such technology at the algorithm level will be able to provide competent legal assistance. On the other hand, the way law firms and legal departments function will change as blockchains become more commonplace in both public administration and various sectors of the economy. Document registers will be created in blockchain, and this will do away with the need for archives of paper documents, change the way in which contracts are prepared and, as a result, improve many internal processes and reduce operating costs. 